\title{
Impact of Image and Satisfaction on Marketing Innovation
}

\author{
Alexander Zuñiga-Collazos ${ }^{\star 1}$, Marysol Castillo-Palacio ${ }^{2}$
}

\begin{abstract}
Colombia is a country that has achieved significant tourism growth in recent years. However, both research and empirical evidence about its tourism development is very limited. Marketing innovation in tourism enterprises is one of the keys to this country maintaining positive tourism development. This empirical study analyzed marketing innovation in 364 of Colombia's tourism companies. The findings show that "satisfaction" in terms of application of innovative marketing strategies that improve customer satisfaction and "image" in terms of application of innovative marketing strategies that help to improve image of company's products and services have a significant relationship with marketing innovation of Colombia's tourist enterprises.
\end{abstract}

Keywords: Marketing innovation; tourism innovation; image; customer satisfaction; Colombia

Submitted: March $4^{\text {th }} 2016 /$ Approved: June $7^{\text {th }} 2016$

\section{Introduction}

In the last two decades there has been growing interest in the topic of innovation in tourism, focusing on different types of innovation in products, processes, marketing, and organizational management. Researchers have also explored potential determinants of innovation in the tourism industry (Hjalager, 2010; Medina-Muñoz et al., 2013). In particular, marketing innovation on tourism industry is a topic of interest to scientific community (Lee et al., 2015; Alizadeh \& Isa, 2015; Gössling \& Lane, 2015; Zuñiga-Collazos et al., 2015; Carvalho \& Sarkar, 2014).

In the case of Colombia, this country has experienced a significant growth on tourism industry over the past decade, According to Ministry of Commerce, Industry, and Tourism of this country the number of visitors has quadrupled in the recent decade (200-2010), with 557.280 visitors to 2.15 million respectively. However, despite the positive development of tourism, Colombian tourism enterprises are facing challenges of competitive tourism and his research and empirical evidence on innovation in tourism enterprises remains very limited (Zuñiga-Collazos, 2015). Consequently, there is a gap in order to understand growth in Colombia's tourism industry and the enterprises that provide the industry's foundation. The purpose of this study is to analyze the relationship between marketing innovation of Colombia's tourist enterprises (MICTE) in a sample of small and medium tourism enterprises using conceptual variables: marketing innovation as the dependent variable and satisfaction and image as two factors that measure marketing innovation as independent variables.

\section{Marketing Innovation.}

According with Organization for Economic Co-operation and Development OECD \& Eurostat (2005) there exist four types of innovation: (1) product innovations, referring to significant change in the characteristics of goods and services, meaning new products and improved existing products; (2) process innovations, referring to significant changes in the methods of product and distribution; (3) organizational innovations, referring to the implementation of new methods of organizations; and (4) marketing innovations, referring to all practices of developing new marketing processes, marketing, and selling products or services. Marketing innovation is "the implementation of a new marketing method involving significant changes in product design or packaging, product placement, product promotion or pricing. Marketing innovations are aimed at better addressing customer needs, opening up new markets, or newly positioning a firm's product on the market, with the objective of increasing the firm's sales" (OECD \& Eurostat, 2005)

On other hand, organizational strategy and innovation interact for two reasons. The market-driving reason focuses on developing new market needs; in order to obtain a high satisfaction, customers have to be persuaded about new types of products and services. This is where marketing innovation leads to strategy (Menon et al., 1999; Verhoef \& Leeflang, 2009). Besides marketing innovation activities can help firms to enter and satisfy new markets (OECD \& Eurostat, 2005; Schubert, 2010; Varis \& Littunen, 2010). The rationale here is that a firm that have innovation in marketing may better understanding of both customer needs to satisfy, and the ability to have a very good image of products and services offered.

In the literature exists empirical evidence about enterprises of both industrial and services sector as tourism that are based on understanding of innovation in marketing and its relationship with other variables such as performance or other (Huhtala et al., 2014; Ceylan, 2013; Arnett \& Wittmann, 2014; Atalay et al., 2013). Nicolau and Santa-María (2013) suggest than the marketing innovation have a higher positive effect on performance hotel, which is explained by potential cost differences among innovations. Finally according by Hjalager (2010), marketing innovation is so important that it has led tourism literature to consider as a separate category to study.

(1) Faculty of Economics Sciences, University of San Buenaventura, Cali, Colombia.

(2) University of Las Palmas de Gran Canaria (ULPGC), Spain.

*Corresponding author: azuniga01@usbcali.edu.co 


\section{Satisfaction and Marketing Innovation.}

Kotler (2000) considered customer satisfaction as a mental state which results from customer's comparison of expectations prior to a purchase with performance perceptions after a purchase. In addition, customer satisfaction is the customer's assessment of a service in terms of whether that service has met the customer's needs and expectations (Zeithaml et al., 2006). Therefore, it can consider consumer satisfaction as response based on evaluations and expressed some time during the purchase-consumption process (Lee et al., 2015), where is possible that a good marketing innovation can influence positively. In this sense, Lee et al., (2015) investigated the effects of attitude toward using mobile app services on customer satisfaction. These authors were based on a questionnaire survey of 538 respondents in Taiwan and the path analysis result demonstrated that usage attitude of this marketing innovation is the most significant factor for customer satisfaction.

On the other hand, according by the Innovation Diffusion Theory (IDT), proposed by Rogers (1983). IDT includes five significant innovation characteristics: relative advantage, compatibility, complexity, trialability, and observables. More specifically, compatibility measures a technology's consistency with users' values, past experience, and needs (Rogers, 1995). Agarwal and Prasad (1999) describe a positive relationship between an individual's prior compatible experiences and acceptance of new innovation, and satisfaction. In this sense, Lee et al., (2015) describe as use apps as a marketing innovation improve customer satisfaction.

Finally, from a strategic marketing perspective, innovation and competitive advantage are closely related concepts (Porter, 1991); and all kinds of marketing innovation, if effectively managed, can contribute toward generating advantage (Naidoo, 2010; Desouza et al., 2009).

\section{Image and innovation Marketing}

Overall image of an enterprise might have an impact on consumer buying behaviors (Homburg \& Giering, 2001; Han \& Back, 2008; Hillery et al., 2001). Some authors use the concepts of reputation and image interchangeably (Barnett et al., 2006; Stern et al., 2001). But, in literature about image concept related with innovation marketing are limited. However, Frank et al. (2015) introduces the concept of innate willingness to pay for innovations (IWTPI). Based on a questionnaire, authors collected consumer data from Germany, Indonesia, Bolivia, USA, and Japan; it tests hypotheses about the antecedents to IWTPI, the moderating effects of IWTPI on the formation of customer satisfaction, and their differences between products and services. Results show that IWTPI tends to be positively influenced by importance of status symbols as image. Moreover, these effects are moderated by cultural and economic factors and the effects of IWTPI are positively moderates by public brand image of company. In others words, the innovations realized on companies's image would have positive impact on possibility to pay for this type of innovations in marketing.
Finally, innovation marketing based on image may impact more stronger in terms of IWTPI when increase the importance of social recognition, which is the a posteriori perception that using certain products and services has led to positive social feedback and thus represents experienced social benefits (Choi et al., 2014; Frank, 2012; Frank et al., 2014). This effect may be even stronger than reported in the literature on consumer innovativeness because willingness to pay for innovations presupposes a greater return on investment, in terms of social recognition, than mere interest in innovations (Frank et al., 2015).

\section{Methodology}

According to Cohen and Cohen (1983) and Hair et al. (1995) regression analysis is useful because it can (1) explain the relationship between one variable with others and (2) estimate the behavior of a variable based on what is known of other variables that influence that variable's behavior.

In this study, this technique can explain the relationship between the independent variables and the Marketing Innovation of Colombia's Tourist Enterprises (MICTE) or for predicative purposes, estimate the behavior of MICTE and determine the influence of independent variables satisfaction and image. The suggested model has the following structure determined by the dependent variable:

$\operatorname{MICTE}=\beta_{0}+\beta 1 \bullet$ Inn-Mark $1+\beta 2 \cdot$ Inn-Mark

Where: MICTE = Marketing Innovation of Colombia's Tourist Enterprises; $\beta_{0}=$ Constant; Inn-Mark $=$ Satisfaction: application of innovative marketing strategies that improve customer satisfaction (actions taken to improve satisfaction); Inn-Mark $=$ Image: application of innovative marketing strategies that help to improve image of company's products and services (actions taken to improve the image).

\section{Sampling}

A survey was designed and applied to a representative sample of 364 managers with tourism enterprises in the cities of Medellin, Calarca, Popayan and Santander de Quilichao. Data collected for the study contain a sample of different tourism businesses, including 74 (20.33\%) hotels, 203 (54.77\%) restaurants, 14 (3.58\%) travel agencies, 24 (6.59\%) companies providing hosting services, and 49 (13.46\%) other types of tourism businesses. The companies surveyed are small and medium enterprises (SMEs). According to the Ministry of Commerce, Industry, and Tourism of Colombia the sample included, by firm size: $0-10$ workers, called micro-enterprise $(82.7 \%$ of the sample), 11-50 workers (15.39\%), called small-enterprise, and 51-200 workers (1.61\%), called medium enterprise; $15.43 \%$ of the companies have been established in the market between 2.1 and 4 years, but it is also important to note that $27 \%$ of the companies are start-ups with less than 2 years in the marketplace. 


\section{Analysis}

According to the results presented in the correlation matrix (see Table 1), it can be determined that the variables Inn-Mark ${ }_{1}$ and Inn-Mark have a significant relationship with respect to the variable MICTE and have also shown that these relationships are positive, as seen by their coefficients. Table 1 shows a positive linear relationship with the dependent variable MICTE with each of the independent variables, so that Mark1 is the variable that contributes the most to the model, due to the fact that this one has the highest correlation coefficient. Regarding the evaluation of the correlation of the residues is highlighted the problem to evaluate the Durbin-Watson indicator, which is close to $0: 1.966$. It is also important to note the high significance of the model $(\mathrm{F}=3985.304$ and $\mathrm{p}=0.000)$.

On the other hand, as observed in the coefficient matrix (see Table 1), there are no problems of multi-collinearity; therefore, for each of the variables, their tolerance indicator is not less than 0.10 , as suggested by the theory of Menard (1995) (cited by Aldás, 2008). Finally, the detection of outliers is calculated by the Mahalanobis distance and its significance, using the method suggested by Aldás (2008). According to the analysis, none of the analyzed data shows a statistically significant Mahalanobis distance $(\mathrm{p}<0.001)$ to infer the existence of an outlier.

Table 1. Correlation Matrix $(\mathrm{N}=364)$

\begin{tabular}{lccc}
\hline & MICTE & InnMark_1 & InnMark_2 \\
\hline MICTE & 1 & & \\
Person Correlation & & 1 & \\
Inn-Mark & 0.910 & 0.000 & 1 \\
Person Correlation & 0.000 & 0.673 & 0.000 \\
Sig. (Unilaterally) & & 0.000 & \\
Inn-Mark & 0.877 & 0.000 & \\
Person Correlation & & \\
Sig. (Unilaterally) & & & \\
&
\end{tabular}

${ }^{*}$ Correlation is significant at the 0.000 level (unilateral)

Outputs for ANOVA analysis shows that the significance level for the $F$ test of the regression is 0.000 , that is lower than 0.05 as the minimum level of significance expected; therefore, the hypothesis $\mathrm{H} 0$ is rejected, and must be at least $\beta \neq 0$, and thus at least some of the independent variables explain the behavior of the dependent variable MICTE. Subsequently, the significance of the parameters is evaluated individually. For this the $t$ test is evaluated in the coefficient matrix, taking into account the hypotheses $\mathrm{H} 0: \beta \mathrm{j}=0$ and $\mathrm{H} 1: \beta j \neq 0$.
According to Table 2 (matrix of coefficients), Inn-Mark ${ }_{1}$ and InnMark $_{2}$ have a significant individual significance within the model, and therefore could be argued that the variables contribute to it. Whit respect to the model, it appears to be a good fit, and we can say that with a corrected $\mathrm{R}^{2}$ of 0.956 , the model is explaining $95.6 \%$ of the information with the variables used, namely Inn-Mark ${ }_{1}$ and Inn-Mark ${ }_{2}$. The remaining $4.4 \%$ of the information can be explained by other variables that have not been taken into account in the model.

Table 2. Matrix of Coefficients

\begin{tabular}{|c|c|c|c|c|c|c|c|}
\hline \multirow[t]{2}{*}{ Model } & \multicolumn{2}{|c|}{ Unstandardized Coefficients } & \multirow{2}{*}{$\begin{array}{c}\text { Typified } \\
\text { Coefficients } \\
\text { Beta }\end{array}$} & \multirow{2}{*}{$t$} & \multirow{2}{*}{ Sig. } & \multicolumn{2}{|c|}{ Statistical Collinearity } \\
\hline & B & Typ. Error & & & & Tolerance & FIV \\
\hline (Constant) & 0.113 & 0.037 & & 3.034 & 0.003 & & \\
\hline Inn-Mark & 0.525 & 0.013 & 0.585 & 39.503 & 0.000 & 0.547 & 1.827 \\
\hline
\end{tabular}

Dependent Variable: MICTE. $F=3985.304 ; \rho=0.000$

Once the validity of the model results is confirmed, the regression line obtained from the coefficient matrix (see Table 2) is:

MICTE $=0.113+0.585 \bullet$ Inn-Mark $1+0.484 \bullet$ Inn-Mark 2

With this equation, we can predict the level of marketing innovations that a particular company will have, if we understand their perceptions. However, to also predict the degree of Colombia's tourist enterprises marketing innovations, the regression coefficients aditionally allow identifying the relative importance of individual variables to predict. In this case it is clear that the variable InnMark ${ }_{1}$ is the most important (0.585), followed by Inn-Mark 2 (0.484).

The study results are summarized in Table 3. 
Table 3. Regression Results

\begin{tabular}{rccc}
\hline Model & $\mathrm{B}$ & $\mathrm{SE}$ & $\mathrm{B}$ \\
(Constant) & 0.113 & 0.037 & \\
Inn-Mark $_{1}$ & 0.525 & 0.013 & $0.585^{\star}$ \\
Inn-Mark $_{2}$ & 0.439 & 0.013 & $0.484^{*}$ \\
\hline & $\mathrm{R}^{2}=0.956 ;{ }^{*} \rho<0.001$ &
\end{tabular}

\section{Results}

The implementation of marketing innovation activities in Colombian tourist companies is an emerging practice, and according to the results of this study, they spend relatively little effort in achieving this type of innovation. This finding is true for each aspect of innovation. Inn-Mark ${ }_{1}$, which is satisfaction understood as application of innovative marketing strategies that improve customer satisfaction, had an average rating of 2.72 out of 5.0 by entrepreneurs, thus indicating that the level of changes or improvements in its practices as the way to do actions to improve satisfaction based on innovation marketing as a priority for all companies surveyed. Likewise, when reviewing the data obtained about this innovation type, it appears that there are companies that have made little effort in this direction, and others who have done their best to contribute to this task so that not all have the same level of intent to innovate from the satisfaction. Inn-Mark which is image understood as the way to application of innovative marketing strategies that help to improve image of company's products and services, had an average rating of 2.93 out of 5.0 on the part of employers, indicating that the level of actions in order to improve imagen based on marketing innovation is not being carried out as a priority in all companies surveyed, and compared to the generation of improvements in this type of innovations is not a task given priority. Likewise, reviewing the minimum and maximum rating obtained, it appears that there are companies that have made little effort in this direction, and others have made some effort to do so, so that not all have the same level of intent to improve or obtain new forms of marketing innovation for company. In general this study shows that research and development is given a low priority by Colombian tourism companies.

\section{Conclusions}

The results allow a better understanding of the relationship between marketing innovations in the tourism sector. They also provide important empirical evidence supporting the theoretical conceptualization described by Lee et al., 2015; Agarwal and Prasad, 1999; Lee et al., 2015; Homburg and Giering, 2001; Han and Back, 2008; Hillery et al., 2001; Frank et al., 2015, and these results increase this type of evidence for companies located in less developed destinations, where the dynamic and context is different from more established destinations. This could justify the difference in the correlation between Inn-Mark , Inn-Mark $_{2}$ with MICTE. These correlations are described below. For less developed countries, marketing innovation should be addressed as a major determining factor in sustained tourism. In connection with how well the model fits, we can say that with a correlated $\mathrm{R}^{2}$ of 0.956 , the model is explaining $95.6 \%$ of the information with the variables used, namely Inn-Mark1 and Inn-mark ${ }_{2}$, while the remaining $4.4 \%$ of the data can be explained by other variables that have not been taken into account in the model.

The main conclusion of this study is the observation of a significant relationship regarding the MICTE with the variables Inn-Mark

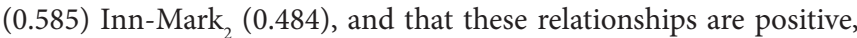
as shown by their coefficients. In sum, there exists a positive linear relationship between the dependent variable MICTE with the independent variables Inn-Mark ${ }_{1}$ and Inn-Mark ${ }_{2}$, and Inn-Mark ${ }_{1}$ is the variable that contributes the most to the model. In order to predict the degree of Colombia's tourist enterprises marketing innovations, the regression coefficients allow identifying the relative importance of individual variables to predict the important level of this type of innovation. In this case, it is clear that the variable Inn-Mark ${ }_{1}$ is the most important (0.585), followed by Inn-Mark 2 (0.484).

Finally, this study presents some limitations. In order to expand the sample to a larger number of cities in the country, it is recommended that in future studies the sample can be extended to cities with relatively good tourist development. On the other hand, future research should identify correlations of other innovation variables as process innovation.

\section{References}

Aldás, J. (2008). El análisis de regresión. Apuntes de Clase. Universitat de València. Departamento de Comercialización e Investigación de Mercados, Valencia, Spain

Alizadeh, A. \& Isa, R. M. (2015). The use of social media in destination marketing: An exploratory study. Tourism, 63(2), 175-192. UDC: 338.487:659.1]:316.774

Atalay, M., Anafarta, N. \& Sarvan, F. (2013). The relationship between innovation and firm performance: An empirical evidence from Turkish automotive supplier industry. Procedia-Social and Behavioral Sciences, 75, 226-235. doi:10.1016/j.sbspro.2013.04.026

Agarwal, R. \& Prasad, J. (1999). Are individual difference germane to the acceptance of new information technologies? Decision Sciences, 30(2), 361-391. doi: 10.1111/j.1540-5915.1999.tb01614.x

Arnett, D. B. \& Wittmann, C. M. (2014). Improving marketing success: The role of tacit knowledge exchange between sales and marketing. Journal of Business Research, 67(3), 324-331. doi:10.1016/j. jbusres.2013.01.018

Barnett, M. L., Jermier, J. M., \& Lafferty, B. A. (2006). Corporate reputation: The definitional landscape. Corporate reputation review, 9(1), 26-38. doi:10.1057/palgrave.crr.1550012

Carvalho, L. M. C. \& Sarkar, S. (2014). Market structures, strategy and innovation in tourism sector. International Journal of Culture Tourism and Hospitality Research, 8(2), 153-172. doi.org/10.1057/palgrave. crr.1550012 
Ceylan, C. (2013). Commitment-based HR practices, different types of innovation activities and firm innovation performance. The International Journal of Human Resource Management, 24(1), 208-226. doi.org/10.1080/09585192.2012.680601

Choi, J., Lee, H.J., Sajjad, F. \& Lee, H. (2014). The influence of national culture on the attitude towards mobile recommender systems. Technological Forecasting and Social Change, 86, 65-79. doi:10.1016/j. techfore.2013.08.012

Cohen, J. \& Cohen, P. (1983). Applied multiple regression/correlation analysis for the behavioral sciences (2nd Ed.). Hillsdale, NJ: Lawrence Erlbaum.

Desouza, K., Dombrowsky, C., Awazu, Y., Baloh, P., Papagari, S., Jha, S. \& Kim, J. (2009). Crafting organizational innovation processes. Innovation: Management, Policy \& Practice, 11(1), 6-33.

Frank, B., (2012). The formation of consumer attitudes and intentions towards fast food restaurants: how do teenagers differ from adults? Management Service Quality, 22 (3), 260-282. doi. org/10.1108/09604521211230987

Frank, B., Herbas Torrico, B., Enkawa, T. \& Schvaneveldt, S.J., (2014). Affect vs. cognition in the chain from perceived quality to customer loyalty: the roles of product beliefs and experience. Journal Retail. 90 (4), 567-586. doi:10.1016/j.jretai.2014.08.001

Frank, B., Enkawa, T., Schvaneveldt, S. J. \& Torrico, B. H. (2015). Antecedents and consequences of innate willingness to pay for innovations: Understanding motivations and consumer preferences of prospective early adopters. Technological Forecasting and Social Change, 99, 252-266. doi:10.1016/j.techfore.2015.06.029

Gössling, S. \& Lane, B. (2015). Rural tourism and the development of Internet-based accommodation booking platforms: a study in the advantages, dangers and implications of innovation. Journal of Sustainable Tourism, 23(8-9), 1386-1403. doi:10.1080/09669582.2014.909448

Hair, J.F., Anderson, R.E., Tatham, R.L. \& Black, W. (1995). Multivariate data analysis (4th Ed.). Englewood Cliffs, NJ: Prentice Hall

Hjalager, A. M. (2010). A review of innovation research in tourism. Tourism Management, 31(1), 1-12. doi:10.1016/j.tourman.2009.08.012

Han, H. \& Back, K. J. (2008). Relationships among image congruence, consumption emotions, and customer loyalty in the lodging industry. Journal of Hospitality \& Tourism Research, 32(4), 467-490. doi:10.1177/1096348008321666

Homburg, C. \& Giering, A. (2001). Personal characteristics as moderators of the relationship between customer satisfaction and loyalty-an empirical analysis. Psychology \& Marketing, 18(1), 43-66. doi:10.1002/1520-6793(200101)18:1
Hillery, M., Nancarrow, B., Griffin, G. \& Syme, G. (2001). Tourist perception of environmental impact. Annals of Tourism Research, 28(4), 853-867. doi:10.1016/S0160-7383(01)00004-4

Huhtala, J. P., Sihvonen, A., Frösén, J., Jaakkola, M. \& Tikkanen, H. (2014). Market orientation, innovation capability and business performance: Insights from the global financial crisis. Baltic Journal of Management, 9(2), 134-152. doi.org/10.1108/BJM-03-2013-0044

Kotler, P. (2000). Marketing Management: Analysis, Planning, Implementation, and Control, $10^{\text {th }}$ ed., Upper Saddle River, Prentice Hall, NJ.

Lee, C. Y., Tsao, C. H, \& Chang, W. C. (2015). The relationship between attitude toward using and customer satisfaction with mobile application services: An empirical study from the life insurance industry. Journal of Enterprise Information Management, 28(5), 680697. doi.org/10.1108/JEIM-07-2014-0077

Lee, T. R., Kuo, Y. H. \& Hilletofth, P. (2015). Formulation of marketing information and communication strategies in Taiwan tourism industry. International Journal of Innovation and Learning, 18(2), 250-255.

Medina-Muñoz, D. R., Medina-Muñoz, R. D. \& Zúñiga-Collazos, A. (2013). Tourism and innovation in China and Spain: a review of innovation research on tourism. Tourism Economics, 19(2), 319-337. doi. org/10.5367/te.2013.0198

Menon, A., Bharadwaj, S.G., Adidam, P.T. \& Edison, S.W. (1999). Antecedents and consequences of marketing strategy making: A model and a test. Journal of Marketing, 63, 18-40. doi:10.2307/1251943

Naidoo, V. (2010). Firm survival through a crisis: The influence of market orientation, marketing innovation and business strategy. Industrial Marketing Management, 39, 1311-1320. doi:10.1016/j.indmarman.2010.02.005

Nicolau, J. L. \& Santa-María, M. J. (2013). The effect of innovation on hotel market value. International Journal of Hospitality Management, 32, 71-79. doi:10.1016/j.ijhm.2012.04.005

OECD and Eurostat, (2005). - Organization for Economic Co-operation and Development - Manual de Oslo: Guía para la recogida e interpretación de datos sobre innovación. Retrieved from http://www. uis.unesco.org/Library/Documents/OECDOsloManual05_spa.pdf

Porter, P. (1991). Towards a dynamic theory of strategy. Strategic Management Journal, 12, 95-117. doi:10.1002/smj.4250121008

Schubert, T. (2010). Marketing and Organizational Innovations in Entrepreneurial Innovation Processes and their Relation to Market Structure and Firm Characteristics, International Journal of Industrial Organization, 36, 189-212. doi:10.1007/s11151-010-9243-y

Rogers, E.M. (1983). The Diffusion of Innovations, 3rd ed., Free Press, New York, NY. 
Rogers, E.M. (1995). The Diffusion of Innovations, 4th ed., Free Press, New York, NY.

Stern, B., Zinkhan, G. M. \& Jaju, A. (2001). Marketing images Construct definition, measurement issues, and theory development. Marketing Theory, 1(2), 201-224.

Varis, M. \& Littunen, H. (2010). Types of Innovation, Sources of Information and Performance in Entrepreneurial SMEs, European Journal of Innovation Management, 13, 128-154. doi. org/10.1108/14601061011040221
Verhoef, P.V. \& Leeflang, P.S.H. (2009). Understanding the marketing department's influence within the firm. Journal of Marketing, 73, 14-37. doi.org/10.1509/jmkg.73.2.14

Zeithaml, V.A., Bitner, M.J. \& Gremler, D.D. (2006). Service Marketing, Mc Graw-Hill, New York, NY.

Zuñiga-Collazos, A., Harrill, R., Escobar-Moreno, N. R. \& Castillo-Palacio, M. (2015). Evaluation of the Determinant Factors of Innovation in Colombia's Tourist Product. Tourism Analysis, 20(1), 117122. doi.org/10.3727/108354215X14205687167789

Zuñiga-Collazos, A. (2015). Análisis de la investigación y desarrollo turístico en Colombia. Espacios, 36(18), 9. 